\title{
BMJ Open Cross-cultural validation of the Retinopathy Treatment Satisfaction Questionnaire status version (RetTSQs) in Serbian community: a cross- sectional study
}

\author{
Jelena Karadzic, ${ }^{1,2}$ Milenko Stojkovic, ${ }^{1,2}$ Dijana Risimic, ${ }^{1,2}$ Marija Bozic, ${ }^{1,2}$ \\ Nikola Slijepcevic, ${ }^{2,3}$ Snezana Polovina, ${ }^{4}$ Anita Grgurevic ${ }^{5}$
}

To cite: Karadzic J,

Stojkovic M, Risimic D, et al. Cross-cultural validation of the Retinopathy Treatment Satisfaction Questionnaire status version (RetTSQs) in Serbian community: a crosssectional study. BMJ Open 2020;10:e031236. doi:10.1136/ bmjopen-2019-031236

- Prepublication history and additional material for this paper are available online. To view these files, please visit the journal online (http://dx.doi. org/10.1136/bmjopen-2019031236).

AG since deceased.

Received 07 May 2019

Revised 04 September 2019 Accepted 27 November 2019

Check for updates

(C) Author(s) (or their employer(s)) 2020. Re-use permitted under CC BY-NC. No commercial re-use. See rights and permissions. Published by BMJ.

For numbered affiliations see end of article.

Correspondence to Dr Jelena Karadzic; bkjelena@gmail.com

\section{ABSTRACT}

Objective Cross-cultural translation and validation of the Serbian version of the Retinopathy Treatment Satisfaction Questionnaire status version (RetTSQs).

Design Cross-sectional study.

Settings The study was conducted between June 2017 and June 2018 at tertiary care centre in Serbia, Belgrade. Participants A total of 101 patients with diabetic retinopathy (DR) were included. All subjects were evaluated in two consecutive visits, the first during the initial contact to the clinic, while the second 4-6 weeks later.

Main outcome measures Validation of Serbian version of the RetTSQs was the major outcome.

Results Cronbach alpha coefficient of the subscales ranged from 0.783 (positive scale) to 0.811 (negative scale) and for all domains it was excellent at $\alpha=0.829$. The intraclass correlation coefficient was greater than 0.8 for all of the subscales. Univariable analyses revealed that age, gender, education, marital status and working status did not affect the RetTSQ scores, whereas participants with non-proliferative DR reported significantly higher treatment satisfaction (TS) than those with proliferative retinopathy $(p=0.001)$. The group who received laser treatment scored significantly lower than the group without it $(p=0.004)$ regardless of type of performed laser. Positive and statistically significant correlations were found between the RetTSQ score and most of the National Eye Institute Visual Functioning Questionnaire-25 subscales. Conclusion Translated Serbian adaptation of the RetTSQs showed adequate psychometric characteristics as an acceptable, reliable and valid questionnaire. It was well understood by Serbian diabetic patients and it promises to be used in daily clinical work as an instrument for the assessment of TS for patients with DR.

\section{INTRODUCTION}

Diabetic retinopathy (DR) is the most common microvascular complication of diabetes mellitus (DM), and remains one of the three leading causes of severe vision loss in developed countries. ${ }^{1}$ Microvascular

\section{Strengths and limitations of this study}

- A major strength of this work is the potential for the Serbian version of Retinopathy Treatment Satisfaction Questionnaire (RetTSQ) to be used in the future, as no vision-targeted treatment satisfaction questionnaires have been translated into Serbian or/and neither have they been developed in Serbia, especially for diabetic patients.

- In the cross-sectional study design, the association between two variables should be interpreted carefully bearing in mind that this type of study does not include dimension of time and cannot support conclusion of causal relationships.

- Further testing of RetTSQ is required to establish the utility of RetTSQ to measure patient satisfaction of different treatments.

- Although the number of participants was satisfactory in terms of minimal required sample size, the present sample probably does not have sufficient statistical power to identify some differences as statistically significant in this analysis. A rather small sample posed difficulties in the psychometric testing of the included questionnaires.

- We did not evaluate whether the method of conducting a questionnaire influences the final results (eg, self-administered vs face-to-face interview).

complications of diabetes are long-term complications that affects small blood vessels and include retinopathy, nephropathy and neuropathy. Macrovascular complications of diabetes are primarily diseases of the coronary and peripheral arteries and cerebral vasculature. $^{2}$

For patients with diabetes, regular eye examinations are essential for detecting retinal complications and determining whether and/or when to initiate the treatment. ${ }^{3}$ Currently, the main treatment options for DR are laser photocoagulation of the 
retina, intraocular injections of anti-vascular endothelial growth factor agents and vitrectomy. The efforts to improve glycaemic, lipid and blood pressure control are mandatory for reducing the risk of ophthalmic complications associated with diabetes. All these treatments reduce the progression of DR and may increase the chance of small improvements in visual acuity. ${ }^{34}$

Evaluation of these treatments requires not only assessment of their impact on vision but also assessment of individuals' satisfaction with the treatments. ${ }^{5}$ Treatment satisfaction (TS) is defined as the individual's emotional and physical experiences of the relevant aspects and the results of the treatment. ${ }^{67}$ Physicians and patients often do not have the same view of treatment success. Every patient weighs the significant aspects of treatment and determines his or her overall degree of satisfaction ${ }^{8}$ which does not necessarily correspond to the objective treatment goal and visual outcome. Moreover, the patients' satisfaction influences treatment-related behaviours, which in turn, have a strong impact on the success of the treatment and positive lifestyle changes and better glycaemic control. ${ }^{9}$

The Retinopathy Treatment Satisfaction Questionnaire (RetTSQ) is a tool which was designed to measure satisfaction with treatment for $\mathrm{DR}^{7}$ and it is modelled on the Diabetes Treatment Satisfaction Questionnaire ${ }^{10}$ which in turn provide a pattern and item bank in producing TS questionnaires for different conditions. ${ }^{11} 12$ The questionnaire is composed of two versions: RetTSQs (s meaning status) and RetTSQc (c meaning change). The change version measures change in satisfaction with treatment for DR and is used together with the status version. ${ }^{13}$ The RetTSQ was developed in the UK and Germany, and has been translated into a several different languages. ${ }^{14}$ To our knowledge, no vision-targeted TS questionnaires have been translated into Serbian or/and neither have they been developed in Serbia, especially for diabetic patients. The development of new instruments, and/or translation and validation of existing ones to Serbian language is lacking. The objectives of the current paper were to undertake linguistic validation (LV) of the RetTSQs into Serbian and to test the reliability and validity of the interviewer-administered format of the RetTSQs.

\section{METHODS}

\section{Patient and public involvement}

Patients were involved in the LV process with cognitive debriefing interviews. Patients were also involved in the original design of the RetSTQ in the UK and Germany.

\section{Study design and population}

This cross-sectional study of 101 patients with DR was conducted at the Eye clinic of the Clinical Centre of Serbia, Belgrade, between June 2017 and June 2018. All subjects were evaluated in two consecutive visits, the first during the initial contact to the clinic, while the second interview was conducted 4-6 weeks later. All surveys were carried out by a trained research physician (JK) using a face-to-face interview method.

\section{Sample size}

The minimal sample size required to detect a correlation factor of at least 0.3 based on power of 0.80 and significance level of 0.05 was determined to be 85 . It was a convenience sample because of the relatively small number of respondents available.

\section{Phase 1: data collection}

Demographic and health information and data on diabetes and microvascular complications were collected from medical records and the interview with the participant. The Serbian version of RetTSQs and the Serbian version of the National Eye Institute Visual Functioning Questionnaire 25 (NEI VFQ-25) were then administered. The NEI VFQ-25 was chosen because it is a widely used questionnaire to assess the efficacy of treatment for different ocular conditions and has been already translated into the Serbian language and validated. ${ }^{15}$

Eligibility criteria included patients with diabetes older than 18 years, Serbian speaking and no cognitive or hearing impairment, with diagnosis of DR. Subjects with clinically significant coexisting ocular pathology such as glaucoma and age-related macular degeneration were excluded from the study. All patients underwent a complete ophthalmological examination. The stage of DR and macular oedema was classified using one or more methods such as fundus photography, indirect funduscopy, optical coherence tomography or fluorescein angiography. The classification of DR and macular oedema are set using International Clinical Classification System and the Early Treatment Diabetic Retinopathy Study Research Group criteria, respectively. ${ }^{16}{ }^{17}$ This study was performed in accordance with the Declaration of Helsinki.

\section{Phase 2: translation and adaptation of Serbian version of RetTSQ LV process}

The RetTSQ was translated in close collaboration with Professor Clare Bradley. A licence agreement to use the questionnaire in this study was provided by Health Psychology Research (HPR) on her behalf.

Similarly, all interested parties can visit www.healthps ychologyresearch.com for access to questionnaires.

The LV process followed the recommended instructions and guidelines for LV. The UK English original questionnaires were translated into Serbian by two native Serbian speakers working independently. The two translations were discussed with the developer's team to create a single forward translation of each questionnaire. The resulting forward translation was subsequently translated back into English by two native English speakers. Any discrepancies between original and back-translation were discussed with the developer's team and improvements were made where necessary. The resulting draft translation was then used for cognitive debriefing interviews with five patients with 
DR at different stages and with different types of DM represented, recruited from the patients database of the Eye Clinic. A clinician review step was performed by one of the forward translators (JK) before the cognitive debriefing step in keeping with the high-standard LV guidelines required by HPR.

\section{Questionnaire}

The RetTSQ status version consists of 13 items each rated on a 7-point scale, ranging from 0 (least positive option, eg, very dissatisfied) to 6 (most positive option, eg, very satisfied), with a possible range of total score from 0 to 78 , where a higher score indicates greater satisfaction with treatment. The patients' responses can be presented as a profile of scores calculated for each item. The additional item at the end is used for free comments about treatment causing satisfaction or dissatisfaction, which has not already been covered by the questionnaire. The RetTSQs items ask about different aspects of treatment; item 1: overall satisfaction with current treatment; item 2: how well the treatment works; item 3: side effects; item 4: discomfort/pain; item 5: unpleasantness of treatment; item 6: ease/difficulty of the treatment; item 7: apprehension about the treatment; item 8: patient influence on the treatment; item 9: safety of the treatment; item 10: time consuming; item 11: received information about treatment; item 12: encouraging others with diabetic eye problems; item 13: continuity of treatment. The RetTSQs consists of two subscales: positive aspects subscales measured by following seven items (item 1, 2, 8, 9, 11, 12 and 13) and negative aspects subscale measured with the sum of the following six items (item 3, 4, 5, 6, 7 and $10)$. It can be scored as total score or as two subscales, one covering negative experiences such as side effects and pain with possible range $0-36$, and the other one covering positive aspects of treatment such as safety or efficacy with possible range $0-42$. The two subscales have the possibility of combining into single scale with total score range from 0 to 78 . Higher scores represent higher satisfaction of the patient.

\section{Statistical analysis}

Phase 3: reliability

Assessment of the internal consistency (IC) of the RetTSQs total score and subscales was made by calculating Cronbach's alpha coefficient. This coefficient is used in assessing the reliability based on the homogeneity of items within a scale or subscale. According to the Colton guidelines, Cranach's alpha coefficients greater than 0.80 indicates a high level of IC. ${ }^{18}$

The item-total score correlations were calculated by Spearman's correlation analysis. According to general guidelines ${ }^{18}$ items within a scale with lower correlations than 0.30 suggest low/little correlation and items with correlations above 0.70 are considered good to excellent. Values ranging from 0.30 to 0.70 indicate moderate relationship. To test scale homogeneity, corrected item total correlations were calculated.
To evaluate test-retest reliability, intraclass correlation coefficients were computed for all RetTSQ items. The test-retest data were obtained in inquiry performed in 2 weeks time interval recommended by Streiner et al. ${ }^{19}$ The test-retest reliability analyses were performed on data from the 56 participants who finished both interviews. We excluded any patients whose vision had changed for better or worse during that time period. We followed the ratings suggested by Landis and Koch to interpret the results: $0-0.2$ poor, $0.2-0.4$ fair, $0.4-0.6$ moderate, $0.6-0.8$ substantial and $0.8-<1.0$ almost perfect. ${ }^{20}$

\section{Phase 4: validity}

Principle component analysis (PCA) was used to explore the links between the observed items and the possible subscales and to identify the factor structure. The varimax rotation with Kaiser normalization was used to examine the criteria of PCA for identifying the factor structure. The criterion for the number of factors extracted was scree plot.

Confirmatory factor analysis (CFA) was then conducted in order to check how well the factor structure, identified in the PCA, fits the observed data. The goodness of fit indices, that were used to check whether the data fit with the proposed model, included comparative fit indices (CFI), Tucker Lewis Index (TLI), root mean square error of approximation (RMSEA), the normed fit index (NFI) and model $\chi^{2}(\mathrm{CMIN})$. An NFI $\geq 0.9$ was considered to indicate an acceptable fit. A small value of CMIN and a $p$ value $>0.05$ indicate an acceptable model.

Differences in age, gender, level of education, marital status, stage of DR, type of DM treatment, existence of diabetic macular oedema were examined. The association between these demographic and clinically welldefined groups and RetTSQs scoring were examined with Mann-Whitney U test. A significance level of $<0.05$ was considered significant.

Evidence of concurrent validity was obtained by examining correlations between RetTSQs total score and NEI-VFQ subscale scores using Spearman's correlation coefficients, which were assumed to be conceptually related.

\section{RESULTS}

\section{Descriptive characteristics}

The study included 101 patients with DR with mean age of the respondents of $61.7 \pm 10.7$ years. Among them, 66 $(65.3 \%)$ were men and $35(34.7 \%)$ were women. The majority $(92.1 \%)$ had type 2 diabetes, while the others had type 1 diabetes $(7.9 \%)$. The average diabetes duration was 16.5 years, mean recent haemoglobin A1c $8.0 \%$. Diabetes was treated by diet $(\mathrm{n}=2)$, oral antihyperglycaemic agents $(\mathrm{OAG})(\mathrm{n}=31)$, insulin $(\mathrm{n}=31)$, combination OAG and insulin $(\mathrm{n}=35)$ and insulin pump $(\mathrm{n}=2)$. The most common associate conditions were hypertension and hyperlipidaemia $(90.1 \%$ and $47.5 \%$, respectively). The most prevalent microvascular complication 
Table 1 Demographic and clinical characteristic of the study participants

\begin{tabular}{lc}
\hline Variables & Sample, $\mathbf{n = 1 0 1}$ \\
\hline Age (years), mean \pm SD & $61.70 \pm 10.72$ \\
\hline Gender, female, number (\%) & $35(34.7 \%)$ \\
\hline Marital status, number (\%) & \\
\hline Married & $77(76.2)$ \\
\hline Other & $24(23.8)$ \\
\hline Educational status, number (\%) & \\
\hline Elementary school (1-8 years) & $19(18.8)$ \\
\hline Secondary school & $57(56.4)$ \\
\hline Higher school & $11(10.9)$ \\
\hline University degree & $14(13.9)$ \\
\hline Working status, number (\%) & \\
\hline Working & $40(39.6)$ \\
\hline Not working & $8(7.9)$ \\
\hline Pensioner & $53(52.5)$ \\
\hline Smoking status, number (\%) & \\
\hline Yes & $19(18.8)$ \\
\hline No & $56(55.4)$ \\
\hline Former smoker & $26(25.7)$ \\
\hline Physical activity (more than 30 min/day), \\
number (\%) \\
\hline Yes \\
\hline No \\
\hline Missing value & $55(54.5)$ \\
\hline Visual acuity (Snellen), mean $\pm S D$ & $44(43.6)$ \\
\hline Better eye & $2(2)$ \\
\hline Worse eye & \\
\hline Pocal laser coagulation & $0.6869 \pm 0.292$ \\
\hline Ontravitreal injection & $0.5341 \pm 0.339$ \\
\hline Optical coherence tomography & $100(99)$ \\
\hline
\end{tabular}

was polyneuropathy $(45.5 \%)$ while nephropathy was present in $13.9 \%$ of the sample. Other demographic and clinical data for the participants are summarised in table 1 . The participants had also experienced different ophthalmological diagnostics and treatments due to DR (table 1).

\section{Reliability}

Reliability of the Serbian version of the RetTSQs was assessed by IC analysis and item analysis. Cronbach alpha coefficient of the subscales ranged from 0.783 (positive scale) to 0.811 (negative scale) and for all domains, it was excellent at $\alpha=0.829$ (table 2 ).
Table 2 Reliability analysis based on Cronbach's alpha coefficient

\begin{tabular}{ll} 
& Cronbach's alpha coefficient \\
\hline Total score RetTSQ & 0.829 \\
Positive scale RetTSQ & 0.783 \\
Negative scale RetTSQ & 0.811 \\
\hline
\end{tabular}

RetTSQ, Retinopathy Treatment Satisfaction Questionnaire.

Corrected total-item correlation ranged for total score from 0.367 (encouraging others) to 0.652 (discomfort/ pain of the treatment). For the positive subscale, it ranged from 0.354 (safety of the treatment) to 0.598 (influence on the treatment), while for the negative subscale it ranged from 0.320 (time consuming) to 0.746 (discomfort/pain of the treatment).

Regarding test-retest reliability, the intraclass correlation coefficient was greater than 0.8 for all of the items, ranging from 0.855 (safety) to 0.998 (continue/repeat). Evaluation of the reliability of the Serbian version of the RetTSQs is presented in online supplementary appendix table 1.

\section{Validity}

Factor structure

After Varimax rotation, conducted on the 13 items, two factors were extracted based on scree plot, with loadings $51.41 \%$ of total variance (table 3). Extracted factors were compared with the original questionnaire, and name accordingly. Positive experiences loaded on factor 1, such as current satisfaction and safety, showed the highest loading 0.739 for 'treatment working well'. Factor 2 represents negative aspects such as side effects and discomfort/

Table 3 RetTSQ component matrix

\begin{tabular}{llr}
\hline & \multicolumn{2}{l}{ Two factor solution } \\
\cline { 2 - 3 } Item (item number) & \multicolumn{1}{l}{ Component } \\
\hline Current satisfaction (1) & 0.692 & 0.142 \\
\hline Treatment working well (2) & 0.739 & -0.053 \\
\hline Side effects (3) & 0.078 & 0.783 \\
\hline Discomfort/pain (4) & 0.124 & 0.854 \\
\hline Unpleasant (5) & 0.075 & 0.822 \\
\hline Difficult (6) & 0.139 & 0.771 \\
\hline Apprehensive (7) & 0.170 & 0.641 \\
\hline Influence (8) & 0.661 & 0.205 \\
\hline Safety (9) & 0.432 & 0.241 \\
\hline Time-consuming (10) & 0.600 & 0.259 \\
\hline Information (11) & 0.685 & 0.137 \\
Encourage others (12) & 0.608 & 0.012 \\
Continue/repeat (13) & 0.727 & 0.038 \\
\hline
\end{tabular}

Extraction method: principal component analysis. Rotation method: Varimax with Kaiser normalization. 
pain. The highest negative loads were 'pain/discomfort' (0.854). The only item in our study attributed to a different factor compared with the original scale was item 10 'timeconsuming' which loaded 0.600 to positive subscale and 0.259 to negative subscale, so this item corresponded more to the positive aspect (where the loading was higher).

CFA was conducted to assess the construct validity of the questionnaire and these are our results: NFI $=0.624$, TLI $=0.551, \quad$ CFI $=0.684$, RMSEA $0.157 \quad(0.134-0.179)$, $\chi^{2}$ was $220.945(\mathrm{p}<0.001)$. We then tested a model with dropping the item 10 , NFI was 0.663 , TLI $=0.590$, CFI $=0.721$, RMSEA $0.155(0.131-0.180), \chi^{2}$ was 180.360 $(\mathrm{p}<0.001)$.

\section{Construct and content validity}

Univariable analyses revealed that age, gender, education, marital status and working status did not affect the RetTSQ scores, whereas participants with non-proliferative DR (mean RetTSQ total score 66.6) reported significantly higher TS than those with proliferative retinopathy (mean RetTSQ total score 60.4, $\mathrm{p}=0.001$ ). The group who received laser treatment scored significantly lower (mean score 59.6) than the group without it (mean score 67.6, $\mathrm{p}=0.004$ ) regardless of type of performed laser-panretinal laser photocoagulation, focal or combined $(\mathrm{p}=0.120)$ although differences between those who had panretinal laser compared (mean score 59.5) to focal laser (mean score 70.4) were close to statistical significance ( $\mathrm{p}=0.062)$. The presence of diabetic macular oedema did not achieve statistically significance to have impact on TS (mean score for presence and absence of diabetic macular oedema 45.5 and 56.3, respectively, $\mathrm{p}=0.064$ ). On the other hand, participants with different levels of visual impairment showed significant differences in the total score $(\mathrm{p}=0.030)$. The group with visual acuities equal to or less than 0.2 (mean score 32.1) reported significantly less TS than those with the highest visual acuities (better than 0.9) (mean score 56.7, $\mathrm{p}=0.004$ ), but there were no significant differences compared with the group with visual acuity between 0.3 and 0.8 (mean score 46.2, $\mathrm{p}=0.072$ ).

Those living in the city/town reported better present TS than those living in the village/country (mean score 54.8 and 40.7 , respectively, $\mathrm{p}<0.01$ ). On the other hand, there were no significant differences regarding employment and physical activity in TS $(\mathrm{p}=0.936$ and $\mathrm{p}=0.717$, respectively).

\section{Subscales}

For DR stage, visual impairment and laser treatment, the negative subscale and the positive subscale showed differences similar to those of the total score. Participants with advanced DR reported significantly less TS than those with non-proliferative retinopathy (mean scores 42.6 and 54.7, respectively, $\mathrm{p}=0.003$ for positive and mean scores 40.6 and 55.6, respectively, $\mathrm{p}=0.012$ for negative scale). Also, as with the total score, participants who had experienced laser treatment scored significantly less satisfied than those who did not (positive scale mean scores 43.3 and 55.8, respectively, $\mathrm{p}=0.030$, negative scale: mean scores 41.7 and 57.2 , respectively $\mathrm{p}=0.007$ ).

\section{Convergent construct validity}

Positive correlations were found between the RetTSQ scores and all of the NEI-VFQ subscales. For concurrent validity, strong Spearman correlations were detected between scores on most of the RetTSQ subscales and similar domains of the NEI-VFQ. The total scores of RetTSQ were found to correlate significantly with the following NEI-VFQ subscales 'general vision' $(\rho=0.349$, $\mathrm{p}=0.001)$, 'near activities' $(\rho=0.336, \mathrm{p}=0.001)$, 'distance activities' $(\rho=0.443, p<0.001)$, as well as 'colour vision' $(\rho=0.276, p=0.010)$ and 'social functioning' $(\rho=0.355$, $\mathrm{p}=0.001)$. Also, specific NEI-VFQ subscales such as general health, mental health, dependency, driving and peripheral vision domains revealed correlations with the 'RetTSQs Total Score' with following correlation coefficients $\rho=0.223, p=0.036 ; \rho=0.267, p=0.012 ; \rho=0.270$, $p=0.011 ; \rho=0.358, p=0.027 ; \rho=0.247, p=0.020$, respectively. Yet, there were no correlations with the 'ocular pain' subscale. 'near activities', 'distance activities' and 'social functioning' in NEI VFQ-25 correlated with all subscales in RetTSQ (table 4).

\section{DISCUSSION}

According to our knowledge, this research is the first study measuring the psychometric properties of any DR TS instrument in Serbia and except the validation of the original questionnaire, no previous work in this field was done. Our analysis showed that the Serbian version of the RetTSQ status version had remarkable psychometric properties. It is also important to highlight that this scale was acceptable for our diabetic patients, as they did not find any question daunting or inconvenient. There were no significant changes in the description of items during the process of translation and validation.

In our study, satisfactory Cronbach alpha level of 0.829 for the total RetTSQs score indicates adequate IC reliability of the instrument and is in close comparison with the original UK English RetTSQs values (0.90). ${ }^{5}$ All corrected item-total correlations exceeded the accepted cut-off of 0.30 indicating each item was related to the overall scale.

Test-retest reliability at the item level and total level score of RetTSQs was high indicating very good agreement $(>0.8)$. This proves that the questionnaire is a good tool to measure TS consistently over time. This is an important feature for a questionnaire to be used in follow-up studies. ${ }^{15}$

Unforced principal components analysis of the Serbian RetTSQs produced two clean constructs with total variance of $51.41 \%$. This result is similar with the original which explained $56.5 \%$ of total variance. ${ }^{5}$ Eight items provide positive aspects (items 1, 2, 8, 9, 10, 11, 12 and 13), while five subscales gave negative aspects (items 3, 4, 5, 6 and 7). The only item in our study 


\begin{tabular}{|c|c|c|c|c|c|c|c|c|c|c|c|c|}
\hline & GH & GV & OP & NA & DA & SFvd & MHvs & RLvs & Dvs & DR & CV & PV \\
\hline \multicolumn{13}{|c|}{ NSRetTSQ } \\
\hline $\mathrm{CC}$ & 0.175 & $0.213^{\star}$ & 0.118 & $0.225^{\star}$ & $0.316 \dagger$ & $0.223^{*}$ & 0.180 & 0.107 & $0.211^{*}$ & 0.231 & 0.207 & 0.185 \\
\hline Sig. & 0.100 & 0.045 & 0.272 & 0.036 & 0.005 & 0.038 & 0.092 & 0.321 & 0.048 & 0.164 & 0.054 & 0.084 \\
\hline \multicolumn{13}{|c|}{ PSRetTSQ } \\
\hline $\mathrm{CC}$ & 0.160 & $0.374 \dagger$ & $0.285 \dagger$ & $0.365 \dagger$ & $0.412 \dagger$ & $0.335 \dagger$ & $0.260^{*}$ & $0.307 \dagger$ & $0.273^{*}$ & $0.354^{*}$ & $0.268^{*}$ & 0.193 \\
\hline Sig. & 0.133 & 0.000 & 0.007 & 0.001 & 0.000 & 0.002 & 0.015 & 0.004 & 0.010 & 0.029 & 0.012 & 0.072 \\
\hline \multicolumn{13}{|c|}{ TSRetTSQ } \\
\hline $\mathrm{CC}$ & $0.223^{*}$ & $0.349 \dagger$ & 0.199 & $0.336 \dagger$ & $0.443 \dagger$ & $0.355 \dagger$ & $0.267^{*}$ & 0.209 & $0.270^{\star}$ & $0.358^{*}$ & $0.276 \dagger$ & $0.247^{\prime}$ \\
\hline Sig. & 0.036 & 0.001 & 0.063 & 0.001 & 0.000 & 0.001 & 0.012 & 0.051 & 0.011 & 0.027 & 0.010 & 0.020 \\
\hline
\end{tabular}

*Significant at the 0.05 level (two-tailed).

†Significant at the 0.01 level (two-tailed).

CC, correlation coefficient; CV, difficulty with colour vision; DA, difficulty with distance-vision activities; DR, driving difficulties; Dvs, dependency on others because of vision; GH, general health; GV, general vision; MHvs, mental health problems because of vision; NA, difficulty with near-vision activities; NSRetTSQ, negative scale RetTSQ; OP, ocular pain; PSRetTSQ, positive scale RetTSQ; PV, difficulty with peripheral vision; RetTSQ, Retinopathy Treatment Satisfaction Questionnaire; RLvs, role limitations because of vision; SFvs, limitation of social functioning because of vision; sig., significance; TSRetTSQ, total score RetTSQ.

attributed to different factor compared with the original scale was item 10 'time-consuming' which loaded more to the positive aspect. We have checked the reports and the translation again and discussed them, and it seems adequate and understood well. This difference can be explained that many Serbian respondents/patients are probably accustomed to prolong waiting times to appointments so they did not consider this item to be a negative one. The other possible reason could be that diabetic patients give priority to the scheduled appointments due to fear of losing vision in relation to the length of waiting.

CFA of the original 13-item RetTSQ revealed a less than optimal model fit, when the analysis was based on a model from the original study or when it was based on the alternative 12-item model (dropping time consuming item) where indices for this model improved although the results did not provide a satisfactory result. One explanation can be small the sample sizes which are a common problem when collecting questionnaire data or by particularities of our sample.

If the item does not work as intended, there may be a case for removing this item from the subscales while retaining it in the full-scale score. This would mean that both the full scale and positively worded subscale are scored in exactly the same way as in previous language versions and only the negatively worded subscale is different, with one item removed.

Although most of TS questionnaires for other conditions have proved vigorous to the test of time and the development of new treatments, the HIV TS questionnaire no longer has the same subscales that were identified in the original development work. ${ }^{21}$

According to the literature, it was assumed that greater visual reduction and advanced stages of DR, treatment with laser photocoagulation, especially with panretinal laser photocoagulation, have poorer RetTSQ scores compared with their counterparts. ${ }^{5}$ When stages of DR were different between the eyes, stage of the better eye was used for categorisation. As for known groups' validity, we found that existence of proliferative DR and previously performed laser treatment negatively affected TS. This result is in line with the results of Brose and Bradley ${ }^{5}$ who reported that the negative experiences are more strongly linked to progressive retinopathy and more invasive treatment procedure. Özmen $e t a l^{22}$ also pointed out that the presence of any diabetic complications in conjunction with being under invasive therapy negatively affected TS. On the other hand, the study carried out by Alcubierre $e t$ $a t^{23}$ could not find any relationship between TS and the stage of DR while differences were found in some of the specific items regarding the severity of macular oedema. We expected significant relationships with RetTSQ scores and presence of diabetic macular oedema. However, in our study, the patients with diabetic macular oedema rated their TS as slightly worse compared with patients without it, yet the difference did not reach statistical significance $(\mathrm{p}=0.060)$. Literature results ${ }^{523}$ mostly indicated less TS in participants with macular oedema although Brose et al signify that their results should be taken with reserve due to the small sample size. ${ }^{5}$

Univariable analyses in our study revealed that age did not affect the RetTSQ scores. Our findings are in close comparison with the findings of Brose and Bradley ${ }^{5}$ although it could be expected that people as they grow older have more health problems and lower expectations of treatment, therefore they are more likely to be satisfied with treatment. ${ }^{24}$ Also, in our paper, there was no gender difference in RetTSQ scores which differs from the original paper, ${ }^{5}$ where men were more satisfied with the negative aspects of treatment then women. Literature results mostly indicated worse TS among women compared with 
men. ${ }^{25}{ }^{26}$ In the present study, those living in the city/ town reported better present TS than those living in the village/country. These findings may be explained by a lower accessibility of specialist care among rural residents compared with urban inhabitants.

As an indicator of a good convergent validity, RetTSQ total scores are expected to be significantly correlated with NEI-VFQ subscales as diabetes retinopathy is a chronic condition with a wide spectrum of ocular discomfort and vision-related disability. In our study, the total RetTSQ score correlated significantly with moderate coefficients with almost all NEI-VFQ subscales. These correlations between RetTSQ total and almost all NEIVFQ domains confirmed good concurrent validity.

Some potential limitations of this study need to be considered. First of all, in the cross-sectional study design the association between two variables should be interpreted careful bearing in mind that this type of study does not include the dimension of time and therefore cannot support conclusion of causal relationships. Second, when interpreting these results, the size of the study sample definitely should be taken into account. Although the number of participants was satisfactory in terms of the minimal required sample size, the present sample probably does not have sufficient statistical power to identify some differences as statistically significant in this analysis. An important aspect for future studies is to attain a larger sample to get a more reliable result of the psychometric tests. Third, we did not evaluate whether the method of conducting the questionnaire influenced the final results (eg, self-administered vs face-to-face interview). Even though further studies will be needed in the future to address these issues, the RetTSQs is now ready to be used in Serbia in clinical trials of treatments satisfaction for diabetic patients.

\section{CONCLUSION}

The translated Serbian adaptation of the RetTSQ status version showed adequate psychometric characteristics and is therefore an acceptable, reliable and valid questionnaire. It was well understood by Serbian diabetic patients and it therefore has the potential to be used in daily clinical work as an instrument for the assessment of TS for the patients with DR with or without macular oedema.

\section{Author affiliations}

${ }^{1}$ Eye Clinic, Clinical Center of Serbia, Beograd, Serbia

${ }^{2}$ Faculty of Medicine, University of Belgrade, Beograd, Serbia

${ }^{3}$ Centre for Endocrine Surgery, Clinical Center of Serbia, Beograd, Serbia

${ }^{4}$ Clinic for Endocrinology, Clinical Center of Serbia, Beograd, Serbia

${ }^{5}$ Faculty of Medicine, Institute of Epidemiology, University of Belgrade, Beograd, Serbia

Acknowledgements The authors would like to thank Professor Clare Bradley and her team from the Health Psychology Research Unit at Royal Holloway, University of London for supervising the process of translation and validation Serbian version of the Retinopathy Treatment Satisfaction Questionnaire (RetTSQ). The authors would also like to thank Professor Goran Trajkovic for his valuable and constructive suggestions during data analysis. We would like to thank all the participants in the study.
Contributors JK: a major contributor in writing the manuscript, substantial contributions to the conception of the work. MS, DR: gave a final approval of the version to be published. MB, NS: analysed and interpreted data and drafted the manuscript. SP: performed statistical analysis and revising manuscript critically. AG: revising the manuscript critically for important intellectual content. All authors critically reviewed the manuscript. All authors approved the final manuscript.

Funding This investigation was supported by the Ministry of Education, Science and Technological Development of the Republic of Serbia (Grant No. 175042 and No. 175087). The authors received no specific funding for this article.

Competing interests None declared.

Patient consent for publication Not required.

Ethics approval Ethics Committee of the Faculty of Medicine, University of Belgrade and the Institutional Review Board for human subject investigations reviewed and approved the study.

Provenance and peer review Not commissioned; externally peer reviewed.

Data availability statement Data are available upon reasonable request. The datasets used and/or analysed during the current study are available from the corresponding author on reasonable request. Restrictions apply to the availability of RetTSQs, which were used under license for the current study, and so are not publicly available. Professor Clare Bradley is the copyright holder of the RetTSQs and CEO and majority shareholder in Health Psychology Research (HPR), a company set up to license the questionnaires developed in the course of CB's research including the RetTSQs.

Open access This is an open access article distributed in accordance with the Creative Commons Attribution Non Commercial (CC BY-NC 4.0) license, which permits others to distribute, remix, adapt, build upon this work non-commercially, and license their derivative works on different terms, provided the original work is properly cited, appropriate credit is given, any changes made indicated, and the use is non-commercial. See: http://creativecommons.org/licenses/by-nc/4.0/.

Author note Corresponding author was Professor Anita Grgurevic, who unfortunately suddenly passed away few months ago.This way, we would like to inform you that, me (Jelena Karadzic) as the first author, and on behalf of the remaining co-authors, that correspondence will no longer be possible through our dear Professor Grgurevic, but in the future, I will be responsible for further correspondence via my email adress bkjelena@ gmail.com. We notified BMJ Open and the Editor and submitted the authorship agreement form signed by all authors.

\section{REFERENCES}

1 Resnikoff S, Pascolini D, Etya'ale D, et al. Global data on visual impairment in the year 2002. Bull World Health Organ 2004;82:844-51.

2 Cade WT. Diabetes-Related microvascular and macrovascular diseases in the physical therapy setting. Phys Ther 2008;88:1322-35

3 Nentwich MM, Ulbig MW. Diabetic retinopathy - ocular complications of diabetes mellitus. World J Diabetes 2015;6:489-99.

4 Yam JCS, Kwok AKH. Update on the treatment of diabetic retinopathy. Hong Kong Med J 2007;13:46-60.

5 Brose LS, Bradley C. Psychometric development of the retinopathy treatment satisfaction questionnaire (RetTSQ). Psychol Health Med 2009;14:740-54.

6 Weaver M, Patrick DL, Markson LE, et al. Issues in the measurement of satisfaction with treatment. Am J Manag Care 1997;3:579-94.

7 Woodcock A, Plowright R, Kennedy-Martin T, et al. Development of the new retinopathy treatment satisfaction questionnaire (RetTSQ). Proceedings of vision 2005; international Congress series, 1282: 342-6.

8 Anderson Ret al. Development and validation of the insulin treatment satisfaction questionnaire. Clin Ther 2004;26:565-78.

9 Taylor TR. Understanding the choices that patients make. The Journal of the American Board of Family Medicine 2000;13:124-33.

10 Bradley C, Lewis KS. Measures of psychological well-being and treatment satisfaction developed from the responses of people with tablet-treated diabetes. Diabet Med 1990;7:445-51.

11 Barendse SM, Speight J, Bradley C. The renal treatment satisfaction questionnaire (RTSQ): a measure of satisfaction with treatment for chronic kidney failure. American Journal of Kidney Diseases 2005;45:572-9.

12 Mitchell J, Bradley C. Design and development of the MacTSQ measure of satisfaction with treatment for macular conditions used within the IVAN trial. J Patient Rep Outcomes 2018;2:5. 
13 Bradley C. Diabetes treatment satisfaction questionnaire. change version for use alongside status version provides appropriate solution where ceiling effects occur. Diabetes Care 1999;22:530-2.

14 HomeHealth Psychology Research. RetTSQ: Retinopathy Treatment Satisfaction Questionnaire - 14 Questions, 2019. Available: http:// www.healthpsychologyresearch.com/information/currentlyavailable-translated-questionnaires/rettsq-retinopathy-treatmentsatisfaction

15 Kovac B, Vukosavljevic M, Djokic Kovac J, et al. Validation and cross-cultural adaptation of the National eye Institute visual function questionnaire (Nei VFQ-25) in Serbian patients. Health Qual Life Outcomes 2015;13:142.

16 Wilkinson CP, Ferris FL, Klein RE, et al. Global diabetic retinopathy project group: proposed Internacional clinical diabetic retinopathy and diabetic macular edema disease severety scales. Ophthalmology 2003;110:1677-82.

17 Early Treatment Diabetic Retinopathy Study Research Group. Early photocoagulation for diabetic macular retinopathy. ETDRS report number 9. Ophthalmology 1991;98:766-85.

18 Colton T. Statistics in medicine. 1st ed. Boston: Little, Brown, 1974.

19 Streiner DL, Reliability NGRStreiner DL, Norman GR, eds. Health measurement scales : a practical guide to their development and use. 2nd ed. Oxford: Oxford University Press, 1995: 79-96.
20 Landis JR, Koch GG. The measurement of observer agreement for categorical data. Biometrics 1977;33:159-74.

21 Romaine J, Murray M, Bradley C. Psychometric evaluation of the revised HIV treatment satisfaction questionnaire (Hivtsq). Value in Health 2016;19:A420.

22 Özmen B, Eser E, ÖzkayaKafesçiler S, et al. Psychometric properties and responsiveness of the Turkish version of the diabetes treatment satisfaction questionnaire (S) on a sample of diabetics of three consecutive monitoring periods. ActaDiabetol 2010;47:123-31.

23 Alcubierre N, Rubinat E, Traveset A, et al. A prospective crosssectional study on quality of life and treatment satisfaction in type 2 diabetic patients with retinopathy without other major late diabetic complications. Health Qual Life Outcomes 2014;12:131.

24 McMillan C, Bradley C, Razvi S, et al. Psychometric evaluation of a new questionnaire measuring treatment satisfaction in hypothyroidism: the ThyTSQ. Value in Health 2006;9:132-9.

25 Nicolucci A, Cucinotta D, Squatrito S, et al. Clinical and socioeconomic correlates of quality of life and treatment satisfaction in patients with type 2 diabetes. Nutrition, Metabolism and Cardiovascular Diseases 2009;19:45-53.

26 Wredling R, Stålhammar J, Adamson U, et al. Well-Being and treatment satisfaction in adults with diabetes: a Swedish populationbased study. Qual Life Res 1995;4:515-22. 